\title{
Correlation of End-Tidal Carbon Dioxide Tension with Arterial Carbon Dioxide Tension in Patients with Respiratory Failure on Mechanical Ventilation Hamdy Zoair, Ahmed Ewis, Islam Ezzat
}

Department of Chest Diseases, Faculty of Medicine, Al-Azhar University, Cairo, Egypt. corresponding author: Islam Ezzat,email: islamezzat000@gmail.com

\begin{abstract}
Background: Patients undergo mechanical ventilation need continuous evaluation of their respiratory condition. Monitoring of end-tidal carbon dioxide $\left(\mathrm{ETCO}_{2}\right)$ as noninvasive measurement of arterial carbon dioxide $\left(\mathrm{PaCO}_{2}\right)$ is a good tool for assessment and management of mechanically ventilated patients.

Aim of the work: The aim of this work is to correlate expiratory end-tidal carbon dioxide tension with arterial carbon dioxide tension in patients with respiratory failure on mechanical ventilation and its significance.

Patients and methods: This study was carried out on 50 patients on invasive mechanical ventilation with acute or acute on top of chronic respiratory failure admitted to respiratory I.C.U. at Bab El- Shaeria University Hospital, Studied patients had obtained two ABG samples one at the onset of mechanical ventilation(M.V.) and the second when the patient was on weaning mode of mechanical ventilation with continuous capnographic monitoring and reading record at the onset of $\mathrm{ABG}$ sampling.

Results: The study include 31 males (62\%), and 19 female (38\%),24 patients (48\%) had C.O.P.D, 9 patients (18\%) had pneumonia, 8 patients (16\%) had O.H.S, 7 patients (14\%) had I.L.D and2 patients (4\%) had acute severe asthma. The study shows no statistical significant difference between $\mathrm{PaCO}_{2}$ and $\mathrm{ETCO}_{2}$ at the onset of mechanical ventilation $(74.78 \pm 20.19$ and67.5 \pm 19.23$) \mathrm{mmHg}$ and on weaning mode $(43.98 \pm 8.07$ and $42.2 \pm 7.2) \mathrm{mmHg}$. that $\mathrm{PaCO}_{2}$ measurements vary approximately $2-7 \mathrm{mmHg}$ above $\mathrm{ETCO}_{2}$ values which mean good correlation between $\mathrm{PaCO}_{2}$ and $\mathrm{ETCO}_{2}$.
\end{abstract}

Conclusion: - $\mathrm{ETCO}_{2}$ measurement provides an accurate estimation of $\mathrm{PaCO}_{2}$ in ventilation and weaning which may reduce the need for invasive, high coast monitoring and repeated arterial blood gas analyses.

Keywords: End-Tidal Carbon Dioxide $\left(\mathrm{ETCO}_{2}\right)$, Respiratory failure (RF), Mechanical Ventilation (MV).

\section{INTRODUCTION}

Patients on mechanical ventilation need continuous evaluation of their respiratory condition. Frequent physical assessment must be complemented by blood gases assessment for complete evaluation ${ }^{(1)}$. Monitoring of end-tidal carbon dioxide tension $\left(\mathrm{ETCO}_{2}\right)$ as a rapid, noninvasive measurement of arterial carbon dioxide tension $\left(\mathrm{PaCO}_{2}\right)$ is one of the methods used for evaluation of mechanically ventilated patients ${ }^{(2)}$. Capnography means continuous analysis and recording of carbon dioxide concentration of respiratory gas which provides in addition to physical assessment a reliable picture of patient condition.

Although the two terms capnometry and capnography are sometimes considered synonymous, capnometry means the measurement of carbon dioxide concentration in respiratory gas, but no continuous record or waveform. Most bedside capnographs use infrared absorption to measure carbon dioxide ${ }^{(3)}$. Gas sample could be obtained by tow methods for analysis. The first is the main stream where the adapter is placed in the breathing circuit. The second is the side stream where gas is aspirated from the breathing circuit and transported through a tube to remote $\mathrm{CO}_{2}$ analyzer ${ }^{(4)}$. Capnography could be performed by trained medical staff in any setting in which mechanically ventilated patients are found ${ }^{(5)}$.

\section{PATIENTS AND METHODS}

\section{Study design}

This study was carried out on 50 patients on invasive mechanical ventilation with acute or acute on top of chronic respiratory failure admitted to respiratory I.C.U. at Bab El- Shaeria University Hospital in the period from January2018 to November 2018. 31 male patients $(62 \%)$, while 19 patients were females $(38 \%)$, 24 patients (48\%) had C.O.P.D, 9 patients (18\%) had pneumonia, 8 patients (16\%) had O.H.S,7 patients (14\%) had I.L.D and 2 patients (4\%) had acute severe asthma.

The study was approved by the local Ethics Committee. Informed written consent was obtained prior to enrollment in the study.

\section{Methods}

The followings were carried out for all patients:

(1)Full medical history:

a- Personal history: name, age, sex, occupation, marital status, residence, smoking and other habits of medical significance. 
Hamdy Zoair et al.

b- Present history: and complain: chest symptoms (dyspnea, fever, cough and chest pain), co-morbidities and drug therapy.

c -Past history: including time of diagnosis, number of previous episodes [exacerbation (s) / hospitalization(s)

/ previous mechanical ventilation] or using of domiciliary oxygen.

(2)Full clinical examination (General and local).

\section{1- General examination}

-Vital signs: pulse, temperature, blood pressure and respiratory rate .

-Central venous pressure, urine output and fluid balance.

- Head and neck examination.

-Heart examination.

-Abdominal examination .

-Lower and upper limb examination.

2-Local chest examination:

Inspection, palpation, percussion and auscultation.

3-Laboratory investigations (CBC, ESR, serum electrolytes, liver and renal profile).

4-Chest radiography (Anetro-posterior view).

5-ECG.

6-Pulse oximetry monitoring.

7-Arterial blood gases analysis:

Studied patients had obtained two ABG samples one at the onset of mechanical ventilation and the second when the patient was on weaning mode of mechanical ventilation.

An ABG specimen was collected in a heparinized blood gas syringe anaerobically and analyzed within 30 minutes. The following parameters and indices were obtained:

-Arterial carbon dioxide tension $\left(\mathrm{PaCO}_{2}\right)(\mathrm{mmHg})$.

-Arterial oxygen tension $\left(\mathrm{PaO}_{2}\right)(\mathrm{mmHg})$. and arterial oxygen saturation $\left(\mathrm{SaO}_{2}\right)$.

-Arterial $\mathrm{pH}$.

-Arterial $\mathrm{HCO}^{-3} \mathrm{mEq} / \mathrm{L}$.

8-Capnography monitoring.

Continuous capnographic monitoring with reading record at the onset of $\mathrm{ABG}$ sampling (mechanical ventilation onset and on weaning mode).

ISA side stream gas analyzer, MASIMO-Sweden with nomoline airway adapter sterilized by $70 \%$ ethanol and connected to Bellavesta1000e ImtmedicalSwitzerland- ventilator used in Bab El-Shaeria respiratory ICU.

\section{Statistical analysis}

Data were analyzed using Statistical Program for Social Science (SPSS) version 15.0.

Quantitative data were expressed as mean \pm standard deviation (SD). Qualitative data were expressed as frequency and percentage.
The following tests were done:

Independent T-test: was used for comparing between two means.

-Probability (P-value)

-P-value $<0.05$ was considered significant.

-P-value $<0.001$ was considered as highly significant. -P-value $>0.05$ was considered insignificant.

\section{RESULTS}

The study included 50 mechanically ventilated patients with respiratory failure 31 male patients $(62 \%)$ while 19 patients were females (38\%). The mean age in studied patients was 60.78 \pm 12.09 years with minimum age of 26 years and maximum age of 81years (range $26-81$ ). 25 patients $(50 \%)$ were heavy smokers, 22 patients (44\%) were nonsmokers while 3 patients $(6 \%)$ were passive-smokers. 24 patients $(48 \%)$ had C.O.P.D, 9 patients (18\%) had pneumonia, 8 patients (16\%) had O.H.S,7 patients (14\%) had I.L.D and2 patients (4\%) had acute severe asthma.(Table 1). The mean $\mathrm{PH}$ was $7.19 \pm$ 0.08.(Table 2).

The study shows no statistical significant difference between $\mathrm{PaCO}_{2}$ and $\mathrm{ETCO}_{2}$ at the onset of mechanical ventilation (74.78 \pm 20.19 and67.5 $\pm 19.23) \mathrm{mmHg}$ and on weaning mode $(43.98 \pm$ 8.07 and 42.2 \pm 7.2 ) that $\mathrm{PaCO}_{2}$ measurements vary approximately $2-7 \mathrm{mmHg}$ above $\mathrm{ETCO}_{2}$ values which mean good correlation between $\mathrm{PaCO}_{2}$ and $\mathrm{ETCO}_{2}$.(Table 3). In studied patients The mean $\mathrm{PaO}_{2}$ was $61.58 \pm 9.69 \mathrm{mmHg}$ The mean $\mathrm{SaO}_{2}$ in was 88.98 \pm 5.65.(Table 4). The description of chest $\mathrm{X}$-ray findings in studied patients was as follow; 16 patients (32\%) showed bilateral lung infiltration, 8 patients (16\%) showed hyper inflated chest, 3 patients $(6 \%)$ showed bilateral lung infiltration and hyper inflated chest, 18patients (36\%) showed hyper inflated chest increased cardiothoracic ratio and bilateral pleural effusion in 5 patients (10\%).(Table 5).

Most common co morbidities in our mechanically ventilated patients were diabetes mellites13 (26\%) and hypertension 11 patients (24\%). Less commonly 5 patients with I.H.D. $(10 \%), 5$ patients with arrhythmias(10\%), 4 patients with heart failure (8\%), 3 patients with C.K.D.(6\%), 2patients with rheumatoid arthritis (4\%) and another 2 patients with cerebrovascular stroke (4\%).(Table 6).

21 Patients (42\%) showed manifestations of corpulmonale as most of the studied patients had chronic chest diseases (Table 7). 
Table (1): Description of age, sex, smoking and chest diseases in studied patients.

\begin{tabular}{|c|c|c|}
\hline \multicolumn{2}{|l|}{ Variables } & Studied patients $(\mathbf{N}=\mathbf{5 0})$ \\
\hline \multirow{5}{*}{ Age (years) } & Mean & 60.78 \\
\hline & \pm SD & 12.09 \\
\hline & Min & 26 \\
\hline & Max & 81 \\
\hline & Range & $(26-81)$ \\
\hline \multirow{2}{*}{ Sex } & Male & $31(62 \%)$ \\
\hline & Female & $19(38 \%)$ \\
\hline \multirow{3}{*}{ Smoking } & Heavy smoker & $25(50 \%)$ \\
\hline & Passive smoker & $3(6 \%)$ \\
\hline & Non smoker & $22(44 \%)$ \\
\hline \multirow{5}{*}{$\begin{array}{l}\text { Chest } \\
\text { disease }\end{array}$} & Acute severe asthma & $2(4 \%)$ \\
\hline & C.O.P.D & $24(48 \%)$ \\
\hline & I.L.D & $7(14 \%)$ \\
\hline & O.H.S & $8(16 \%)$ \\
\hline & Pneumonia & $9(18 \%)$ \\
\hline
\end{tabular}

Table (2): Description of $\mathrm{pH}$ in studied patients.

\begin{tabular}{|c|c|c|}
\hline \multicolumn{2}{|c|}{ Variables } & Studied patients $(\mathbf{N}=\mathbf{5 0})$ \\
\hline \multirow{5}{*}{ pH } & Mean & 7.19 \\
\hline & \pm SD & 0.08 \\
\hline & Min & 7.06 \\
\hline & Max & 7.44 \\
\hline & Range & $(7.06-7.44)$ \\
\hline
\end{tabular}

Table (3): Comparison between $\mathrm{PaCO}_{2}$ and $\mathrm{ETCO}_{2}$ at M.V. onset and weaning mode.

\begin{tabular}{|c|c|c|c|c|}
\hline \multicolumn{2}{|l|}{$\begin{array}{l}\mathrm{CO}_{2} \\
\text { Variables }\end{array}$} & $\begin{array}{l}\mathrm{PaCO}_{2} \\
(\mathrm{~N}=50)\end{array}$ & $\begin{array}{c}\text { ETCO }_{2} \\
(\mathrm{~N}=50)\end{array}$ & P-value \\
\hline \multirow{2}{*}{$\begin{array}{l}\mathrm{CO}_{2}(\mathrm{mmHg}) \\
\text { M.V. }\end{array}$} & Mean & 74.78 & 67.5 & \multirow{2}{*}{0.06} \\
\hline & \pm SD & 20.19 & 19.23 & \\
\hline \multirow{2}{*}{$\begin{array}{l}\mathrm{CO}_{2}(\mathrm{mmHg}) \\
\text { Weaning }\end{array}$} & Mean & 43.98 & 42.2 & \multirow{2}{*}{0.3} \\
\hline & \pm SD & 8.07 & 7.2 & \\
\hline
\end{tabular}

Table (4): Description of $\mathrm{PaO}_{2}$ in studied patients.

\begin{tabular}{||l|l|l||}
\hline \multicolumn{1}{|l|}{ Variables } & Studied patients(N = 50) \\
\hline \hline \multirow{4}{*}{$\mathbf{P a O}_{2}$} & Mean & 61.58 \\
& $\mathbf{\pm S D}$ & 9.69 \\
& Min & 37 \\
& Max & 77 \\
\cline { 2 - 2 } & Range & $(37-77)$ \\
\hline
\end{tabular}

Table (5): Description of chest X-ray in studied patients.

\begin{tabular}{|c|c|c|}
\hline \multicolumn{2}{|c|}{ Variables } & Patients $(\mathrm{N}=\mathbf{5 0})$ \\
\hline \multirow{4}{*}{$\underset{\dot{x}}{\dot{\vec{x}}}$} & Bilateral lung infiltration & \multirow{4}{*}{$\begin{array}{l}16(32 \%) \\
8(16 \%) \\
3(6 \%) \\
18(36 \%)\end{array}$} \\
\hline & Hyper inflated chest & \\
\hline & Bilateral lung infiltration + hyper inflated chest & \\
\hline & Hyper inflated chest +increased c cardiothoracic ratio & \\
\hline
\end{tabular}


Table (6): Description of co morbidities in studied patients.

\begin{tabular}{||l||l|l|}
\hline \multicolumn{1}{|l|}{ Variables } & Studied patients \\
\hline \multirow{5}{*}{ Co morbidities } & A.R.D.S & $4(8 \%)$ \\
& Arrhythmias & $5(10 \%)$ \\
\cline { 2 - 2 } & C.K.D & $3(6 \%)$ \\
\cline { 2 - 2 } & DM & $13(26 \%)$ \\
\cline { 2 - 2 } & HTN & $11(22 \%)$ \\
\cline { 2 - 2 } & IHD & $5(10 \%)$ \\
\cline { 2 - 2 } & H.F & $4(8 \%)$ \\
\cline { 2 - 2 } & Pulmonary edema & $2(4 \%)$ \\
\cline { 2 - 2 } & RA & $2(4 \%)$ \\
\cline { 2 - 2 } & Stroke & $2(4 \%)$ \\
\hline
\end{tabular}

Table (7): Description of cor pulmonale in studied patients.

\begin{tabular}{|l|l|l|}
\hline Variables & Patients $(\mathbf{N}=\mathbf{5 0})$ \\
\hline \multirow{2}{*}{ Cor pulmonale } & Negative & $29(58 \%)$ \\
& Positive & $21(42 \%)$ \\
\hline
\end{tabular}

\section{DISCUSSION}

At the onset of mechanical ventilation A.B.G parameter were as follows:

The mean $\mathrm{pH}$ in studied patients was $7.19 \pm 0.08$.

These findings are in match with Carolyn and Welsh who stated that patients with respiratory failure require ventilation support if they hypoventilate to $\mathrm{pH}<7.25$ with $\mathrm{PCO}_{2}>50 \mathrm{mmHg} .{ }^{(6)}$. The mean $\mathrm{PaCO}_{2}$ at the onset of mechanical ventilation in studied patients was $74.78 \pm 20.19 \mathrm{mmHg}$. The mean $\mathrm{ETCO}_{2}$ at the onset of mechanical ventilation in studied patients was 67.5 $\pm 19.23 \mathrm{mmHg}$. The study showed no statistical significant difference ( $p$-value $>0.05$ ) between $\mathrm{PaCO}_{2}$ and $\mathrm{ETCO}_{2}$ at the onset of mechanical ventilation that $\mathrm{PaCO}_{2}$ measurements vary approximately $2-7 \mathrm{mmHg}$ above $\mathrm{ETCO}_{2}$ values $(74.78 \pm 20.19$ and67.5 \pm 19.23$)$ mmHg which mean good correlation between $\mathrm{PaCO}_{2}$ and $\mathrm{ETCO}_{2}$.

These findings are in match with the study of Razi et al. where where a total of 97 arterial blood gases were obtained from patients (mean age, 71.7 \pm 15 .1years). Statistical analysis demonstrated a good correlation between the mean of $\mathrm{ETCO}_{2}$ and $\mathrm{PaCO}_{2}$ on mechanical ventilation that $\mathrm{PaCO}_{2}$ measurements vary approximately 2-6 $\mathrm{mmHg}$ above $\mathrm{ETCO}_{2}$ values $(48.8$ \pm 17.1 and $42.5 \pm 17.3) \mathrm{mmHg}{ }^{(7)}$.

The present study agreed with Belenkiy et al. study, which demonstrated useful $\mathrm{ETCO}_{2}$ monitoring system during periods of hemodynamic and respiratory instability statistical analysis demonstrated a good correlation between the mean of $\mathrm{ETCO}_{2}$ and $\mathrm{PaCO}_{2}$ on mechanical ventilation $(61.8 \pm 17.9$ and $56.9 \pm 17.3)$ $\mathrm{mmHg}{ }^{(8)}$. Also the present study agreed with the study of Lam et al. which was performed on adult surgical patients and found that capnography provides an early warning of postoperative respiratory distress, especially when supplemental oxygen is administered; with good correlation between the mean of ETCO2 and $\mathrm{PaCO} 2$ on mechanical ventilation $(54.2 \pm 15.9$ and $50.9 \pm 18.3) \mathrm{mmHg}{ }^{(9)}$. The present study disagreed with the study of Mehta et al. which suggested that augmenting standard patient care with $\mathrm{EtCO} 2$ monitoring is a less than optimal solution for detecting changes in respiratory status with high statistical significant difference $(37.2 \pm 4.3$ and $23.3 \pm 4.8)$ $\mathrm{mmHg}$ as this study was carried on non-intubated patients under general anesthesia and spontaneously breathing volunteers ${ }^{(\mathbf{1 0})}$.

The mean $\mathrm{PaO} 2$ in studied patients was $61.58 \pm 9.69$ $\mathrm{mmHg}$. The mean $\mathrm{SaO} 2$ in studied patients was $88.98 \pm 5.65$.

These findings are in match with Bakr et al. study, which comprised 220 patients with acute respiratory failure (ARF) secondary to C.O.P.D., requiring mechanical ventilation (MV) and admitted to the intensive care unit with mean $\mathrm{PaO} 258.4 \pm 7.1 \mathrm{mmHg}$ and $\mathrm{SaO} 288.1 \pm 3.07^{\left({ }^{(1)} \text {. }\right.}$

These findings disagreed with Itagaki et al. study, which was performed on 328 mechanically ventilated patients. The mean $\mathrm{PaO} 2$ in studied patients was $91.5 \pm$ $17.5 \mathrm{mmHg}$ and it was performed on patients with many different causes of mechanical ventilation rather than respiratory failure e.g., postoperative care and altered mental status ${ }^{\mathbf{( 1 2})}$.

On weaning mode, the current study showed no statistical significant difference between $\mathrm{PaCO} 2$ and ETCO2 (43.98 \pm 8.07 and 42.2 \pm 7.2$) \mathrm{mmHg}$.

These findings are in match with Razi et al. study, at which statistical analysis demonstrated a good correlation between the mean of $\mathrm{ETCO} 2$ and $\mathrm{PaCO} 2$ on weaning mode $(39.4 \pm 10.1$ and $37 \pm 9.7) \mathrm{mmHg} .{ }^{(7)}$. 
Also these findings are in match with Bhanot et al. study, which demonstrated a good correlation between the mean of ETCO2 and $\mathrm{PaCO} 2$ on weaning (38.9 \pm 8.1 and $36.2 \pm 7.7) \mathrm{mmHg} .{ }^{(13)}$.

The description of chest X-ray findings in studied patients as follow 16 patients (32\%) showed bilateral lung infiltration, 8 patients $(16 \%)$ showed hyper inflated chest, 3 patients (6\%) showed bilateral lung infiltration and hyper inflated chest, 18patients (36\%) showed hyper inflated chest increased + cardiothoracic ratio and bilateral pleural effusion in 5 patients (10\%). These findings are disagreed with Nurhayati et al. who studied a total 63 subjects 28 males and 35 females. Chest $\mathrm{x}$-ray findings revealed the following conditions: bronchopneumonia (48\%), pleural effusion $(43 \%)$, pulmonary edema $(6 \%)$, and atelectasis $(3 \%)$. None of chest $\mathrm{x}$-ray findings significantly correlated to patient outcomes ${ }^{(\mathbf{1 4})}$.

Most common co morbidities in our mechanically ventilated patients were diabetes mellitus $13(26 \%)$ and hypertension 11 patients (24\%). Less commonly 5 patients with I.H.D, (10\%), 5 patients with arrhythmias (10\%), 4 patients with heart failure (8\%), 3 patients with C.K.D. (6\%), 2 patients with rheumatoid arthritis (4\%) and another 2 patients with cerebrovascular stroke (4\%). During mechanical ventilation 4 patients developed A.R.D.S. (8\%) and 2 patients developed pulmonary edema (4\%).

These findings disagreed with Ongel et al. study, which was performed on 1,013 mechanically ventilated patients 749 male $(73.9 \%)$ and 264 female (26.1\%) with a mean age $70 \pm 10$. Statistical analysis of co morbidities demonstrated 355 patients with hypertension (35\%), 170 patients with D.M. (16.8\%), 141 patients with C.A.D. (13.9\%), 133 patients developed arrhythmia (13.1\%), 38 patients with different types of malignancies $(3.75 \%)$. This study was performed on large number of patients having C.O.P.D. only ${ }^{(15)}$.

\section{CONCLUSION}

-End-tidal $\mathrm{CO}_{2}$ measurement provides an accurate estimation of $\mathrm{PaCO}_{2}$ in ventilation and weaning .

-Capnography could be a potential form for monitoring of mechanically ventilated patients which may reduce the need for invasive, high-coast monitoring and repeated arterial blood gas analyses.

\section{REFERENCES}

1. Kraus A and Baruch E (2003): Capnography in EMS. JEMS.,(10):69-77.

2. https://breathing.com/pages/1000-the-bpcapnotrainer
3. https://www.google.com/search? $q=3 . \% 09 H e s s+D+$ and+Branson+RD+(1994): \&tbm=isch \&source $=$ un iv\&sa=X\&ved=2ahUKEwjsr6i5_YbhAhULtRoK HZjVC2QQ7Al6BAgFEBM\&cshid=

4. Block FE Jr and McDonald JS (1992): Sidestream versus mainstream carbon dioxide analyzers. J Clin Monit.,8(2):139-141.

5. Szaflarski NL and Cohen NH (1991): Use of capnography in critically ill adults.Heart Lung,20(4):363-372.

6. https://www.google.com/search?biw $=1366 \&$ bih $=6$ 57\&tbm=isch\&sa=1\&ei=lxeNXLfDIdCf1fAP9KG t0AM\&q=\%3A+What+are+the+two+major+indic ations+for+mechanical+ventilation+Critical+care +secrets+4th+edition+\%289\%29\%2C51_56\&oq=

7. Razi E, Moosavi GA, Omidi K, Khakpour A and Razi A (2012): Correlation of end-tidal carbon dioxide with arterial carbon dioxide in mechanically ventilated patients. Arch trauma Res., 1(2):58-62.

8. Belenkiy M, William L, Andriy I , Sumit M , Taylor W, Jose S and Leopoldo C (2015) :Multivariate analysis of the volumetric capnograph for $\mathrm{PaCO}_{2}$ estimation. Int J Burn Trauma,5(3):66-74.

9. Lam T, Mahesh N, Jean W, Mandeep S, David W and Frances Ch (2017):Continuous pulse oximetry and capnography monitoring for postoperative respiratory depression and adverse events. AnesthAnalg ,125:2019-2029.

10. Mehta JH, Williams GW, Harvey BC, Grewal NK and George EE (2017): The relationship between minute ventilation and end tidal $\mathrm{CO} 2$ in intubated and spontaneously breathing patients undergoing procedural sedation. PLoS one, 12(6):e0180-187.

11. Bakr M, Ramadan A, Mansour F, Aly A, Fayed F and Sherif A (2012): Predictors of mortality in mechanically ventilated COPD patients. Egyptian Journal of Chest Diseases and Tuberculosis , 61: 6773.

12. Itagaki T, Nakano $Y$, Okuda N, Izawa M, Onodera M, Imanaka $H$, and Nishimura $M$ (2015): Hyperoxemia in mechanically ventilated, critically ill subjects incidence and related factors. Respiratory Care, 60;1-6.

13. Bhanot $D$, Steven $S$, Heath $L$ and Akiko $K$ (2015): End-Tidal Carbon Dioxide $\left(\mathrm{EtCO}_{2}\right)$ as a Surrogate for PaCO2 During Spontaneous Breathing Trial ,Critical Care ,148:1378-88.

14. Nurhayati I, Supriatna M, Raharjani B and Sudijanto E (2013): Correlation between chest X-ray findings andoutcomes of patients with mechanical ventilation. PaediatrIndones, 53: 6-11.

15. Ongel A, Zuhal K, Cuneyt S, Huriye T, Bunyamin B, Feyza K, Gulbanu H, Ozlem M, Gokay G, Nalan $A$ and Adnan Y (2014): How do COPD co morbidities affect ICU outcomes. International Journal of COPD.,9:1187-1196. 